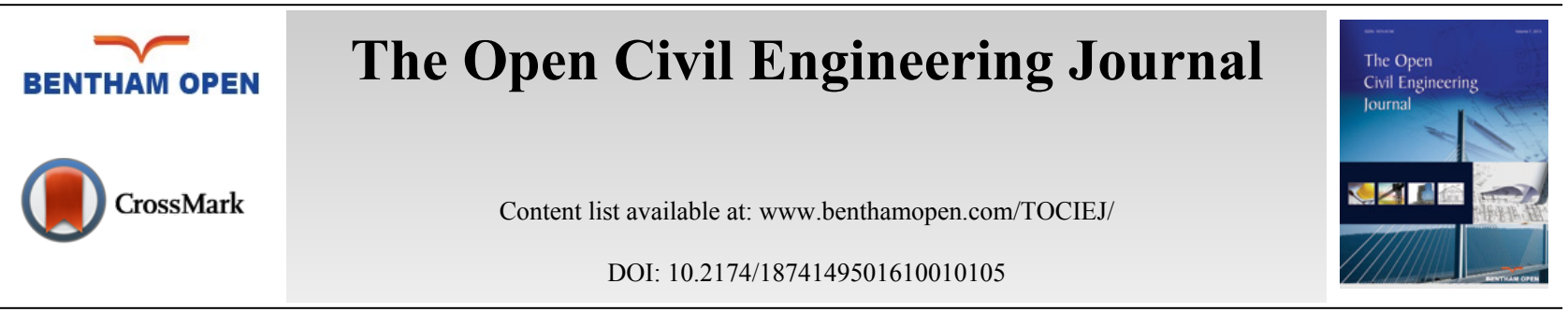

\title{
Stability Analysis of 3D Geonet Slope Protection System in Rainfall
}

\author{
Guangyue Wang", Xinlei Shan and Chuanwen Tu \\ School of Civil and Hydraulic Engineering, Shandong University, Jinan 250061, China
}

\begin{abstract}
Slope protection with 3D geonet is an economic, convenient and eco-friendly technique; and it is increasingly used in practical projects. However, 3D geonet is sensitive to the ambient environment; and it might lose its stability due to rainfall infiltration. In this paper, the overall instability failure of the 3D geonet system under rainfall infiltration is analyzed. By adopting the limit equilibrium method, a slope stability analysis model is established; and the influence of slope angle, rivet space, slope length, rainfall intensity on stability are analyzed, and a formula for calculation of design optimization of rivet space is obtained. The research result would provide technical support for the design and stability analysis of slope protection with $3 \mathrm{D}$ geonet.
\end{abstract}

Keywords: 3D geonet, rainfall intensity, rivet space, slope angel, slope protection, stability.

\section{INTRODUCTION}

3D geonet taking polyoefin polymers as main material is a new slope protection geosynthetics to control soil erosion with three-dimensional structure. The making process is that extrude diamond mesh and biaxially oriented square mesh composite, spot weld and hot compress into a stable three-dimensional network structure (as Fig. 1) and 3D geonet has many advantages: good flexibility, light mass, low price, high tensile strength, excellent corrosion resistance, strong aging resistance, simple construction, easy transportation and so on. 3D geonet slope protecting is a new ecological slope protection technique, and the making process is that expand mesh pads, spread it out on the treated slope, fix it with rivet, sow and cover earth in the grid of mesh pads, then maintain with water. The new slope protection type is effective as well as eco-friendly.

(1) The 3D geonet has obvious action for soil reinforcement and raindrop impact erosion.

(2) The runoff in grid generates small swirl, which is useful for energy dissipation and erosion control.

(3) Plant roots, mesh pads and soil form a strong composite embedment chain system after vegetation formation, which reinforces soil as well.

(4) The slope protection can play a role in slowing down rain erosion and infiltration, extending the runoff path, and reducing water erosion.

Slope vegetation with 3D geonet is an economic, convenient and eco-friendly technique; and it is increasingly used in practical application of modern transportation and water construction [1 - 4]. However, the theoretical research about stability of slope protection of 3D geonet is much slower than practical application and the studies emphasize particularly on construction techniques and protection effect evaluation at present [5 - 8]. For the lack of study in impact of rainfall on 3D geonet, there is no theoretical basis for reference when designing, as a consequence, slope of constructed project is easy to fail, which does not play a great role in side slope protection and even causes economic losses and casualties. So it is significant that stability analysis of 3D geonet slope protection system in rainfall should be studied to provide evidence for industrial design of slope protection of slope protection with 3D geonet.

* Address correspondence to this author at the School of Civil and Hydraulic Engineering, Shandong University, Jinan 250061, China; Tel: +8618769786375; E-mail: 173406459@qq.com 


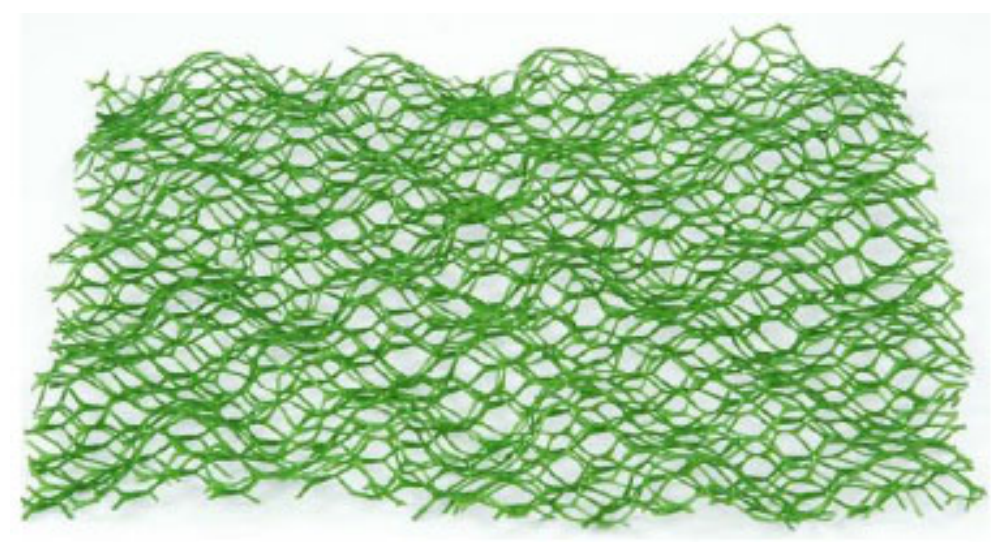

Fig. (1). Structure diagram of 3D geonet.

\section{STABILITY ANALYSIS OF 3D GEONET SLOPE PROTECTION SYSTEM IN RAINFALL}

It can be subdivided into two aspects about stability study of slope protection system with 3D geonet: anti-scouring ability and anti-sliding ability. In the early competition of slope protection system with 3D geonet, for the reason that vegetation minor floor, the stability depends on anchorage action of anchors and friction between the mesh pads and slope soil and that is anti-sliding ability. The influence of rainfall to the stability of slope protection with $3 \mathrm{D}$ geonet shows composite softening effects of rainwater to soil. With rainfall infiltration, the water contents and unit weight $g$ of unsaturated soils increase, while internal friction angle $f$ and the cohesion c decrease, and there would be runoff shear strength and seepage force more than non-rainfall conditions, which contribute to soil shear strength decreasing, stress state changing, slope instability, and overall sliding failure occuring and Fig. (2) shows the stability analyse model of slope protection with tiled $3 \mathrm{D}$ geonet.

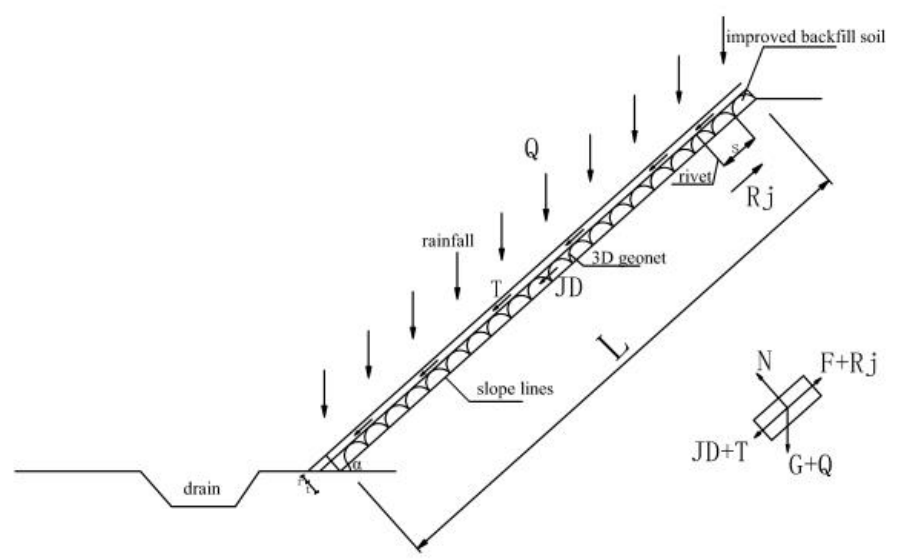

Fig. (2). 3D geonet slope protection system stability analysis model.

Considering that the thickness of 3D geonet is much less than the length of it when installed on original slope, infinite slope method can be adopted, supposing that 3D geonet is a rigid free body, we use limit equilibrium methods to analyse the structure stability. Safety factor $\mathrm{K}$ is defined as the ratio of anti-sliding force $\mathrm{R}$ and sliding force $\mathrm{S}$, that is

$$
K=\frac{R}{S}=\frac{R_{j} / K_{j}+F}{Q+G \sin a+T+J_{D}}
$$

$R_{j}$ : Additional drag of the rivet

$K_{j}$ : Anti-stripping safety factor, generally taking 1.6

$F$ : Friction between the mesh pads and slope soil 
$Q:$ Raindrop impact force

$G \sin \alpha$ : Sliding force of mesh pads soil and mesh pads weight

$T:$ Runoff shear stress

$J_{D}$ : Seepage force

\section{Runoff Shear Stress ( $T$ )}

Slope flow is as Simplified as uniform open channel flow, following are two basic assumptions: (1) Slop infiltration and slop flow would no longer change after slop soil was saturated with water. (2) Slope hydraulic radius equals to runoff depth and the depth has no change throughout the slope.

Based on the uniform open channel flow's basic formula, Chezy formula and Manning formula, we get slope velocity expression [9]:

$$
v=\frac{1}{n} R^{2 / 3} J^{1 / 2}
$$

flux of section:

$$
q=v^{\prime} R^{\prime} 1=I_{12} \cos (a-b)^{\prime} L^{\prime} 1
$$

runoff depth:

$$
R=h=\frac{\left[n I_{12} L \cos (a-b)\right]^{3 / 5}}{43200^{3 / 5} J^{3 / 10}}
$$

runoff shear stress:

$$
T=G \sin a=g_{w} h L \sin a
$$

$C$ : Chezy coefficient

$n:$ Roughness coefficients

$\gamma_{w}$ : Unit weight of water

$h:$ Runoff depth of slope

$J$ : Hydraulic gradient $(J=\sin \alpha)$

$I_{12}(\mathrm{~mm} / 12 \mathrm{~h})$ : Rainfall intensity within 12 hours in China

\section{Raindrop Impact Force $(Q)$}

Resistance law is different when the size of raindrops is different, which is based on raindrops terminal velocity formula according to the size of raindrops diameter [10]:

$$
\left\{\begin{array}{l}
V_{m}=10^{6}\left(\frac{0.787}{r^{2}}+\frac{503}{\sqrt{r}}\right)^{-1} \quad d<1.0 \mathrm{~mm} \\
V_{m}=(1702-0.844 d) \sqrt{0.1 d} \quad 1.0 \mathrm{~mm}<d<3.0 \mathrm{~mm} \\
V_{m}=\frac{d}{0.113+0.0845 d} \quad 3.0 \mathrm{~mm}<d<6.0 \mathrm{~mm}
\end{array}\right.
$$

Raindrops terminal velocity comes to zero within a short time, therefore, it can be seen as a process of momentum variation, and follows Newton's second law, then we get raindrop impact force Q, based on the law of conservation of 
momentum:

$$
Q=\frac{1}{3} p d^{2} r V_{m}^{2} \cos ^{2}(a-b)=\frac{r V_{m} I_{12} A}{43200} \cos ^{3}(a-b)
$$

$d:$ Raindrops diameter

$\rho:$ Rain density

$V_{m}$ : Raindrops terminal velocity

$A$ ( $L \times 1$ in this paper): Calculated area of rainfall

$\alpha$ : Slope angle

$\beta$ : The angle between rainfall direction and gravity direction (the angel in the left of gravity line is positive and in the right is negative)

\section{The Support of Slope To Mesh Pads ( $N$ )}

There is almost no bond consolidation between mesh pads and original slope soils or rocks in parts of lapping and earthing, based on construction specifications of 3D geonet slope protection technology, as a result, 3D geonet and cultivated soil attached to the inner of it is regarded as an independent element, which attached to protection slope. And the support of slope to mesh pads comes mainly from mesh pads, cultivated soil filled in mesh pads, the component of slope steadying flow and Raindrop impact force.

And the expression is as follows:

$$
N=\left[\gamma_{s} t+\gamma_{w} h+g_{n}\right] \cos \alpha+Q
$$

$\gamma_{s}$ : The unit weight of mesh pads filling $\left(\mathrm{kN} / \mathrm{m}^{3}\right)$

$\gamma_{w}$ : The unit weight of water

$g_{n}$ : The weight of mesh pads

$t$ : The thickness of mesh pads

$Q$ : Raindrop impact force

$\alpha$ : Slope angle

\section{Friction $(F)$}

Under the whole slope protection system, 3D geonet is resisted to slide down by slope friction, and $u$ is friction coefficent between mesh pads and slope, determined by slope roughness.

And the expression is as follows:

$$
F=N u=\left(\left[\gamma_{s} t+\gamma_{w} h+g_{n}\right] \cos \alpha+Q\right) u
$$

$u$ : friction coefficent between mesh pads and slope, determined by slope roughness

\section{Additional Drag of The Rivet $\left(\boldsymbol{R}_{j}\right)$}

Suppose geocell protection system per unit width of slope is regarded as a study subject, and rivets are equidistantly distributed in the transverse direction and longitudinal direction. Then additional drag of the rivet can be deduced as follows:

$$
R_{j}=\left(t f_{j} L\right) / s^{2}
$$

$t$ : The thickness of mesh pads 
$f_{t}$ : Tensile strength of $3 \mathrm{D}$ geonet

$s:$ Rivet space (equidistantly distributed in the transverse direction and longitudinal direction)

\section{Seepage Force $\left(J_{D}\right)$}

Seepage refers to the flow of fluid in porous medium. The head loss occurs by resistance of soil when flows in the soil, and a seepage force must be exerted to soil grains when water flows through according to Newton's third law. In order to conveniently research, seepage force of soil grain per unit volume is called seepage force or dynamic waterpower. Seepage force is a kind of body force.

$$
J_{D}=i \gamma_{w} L t=\gamma_{w} L t \sin \alpha
$$

\section{EXAMPLE ANALYSIS}

Take the second contract section of Qingdao-Laiwu highspeed from Qingweijie in China to Mazhan in China of state key Qingdao-Hongqilafu highspeed for example, and some engineering parameters has been known: designed slope angel of soil $\alpha=40^{\circ}$; slope length $L=15 \mathrm{~m}$. Geonet slope protection with greensward technology is adopted, and rivet space $d=1 \mathrm{~m}$; designed rainfall intensity $l_{12}=30 \mathrm{~mm}(\mathrm{~mm} / 12 \mathrm{~h})$, and some planting soil parameters are determined before filling: $\gamma_{d}=17.6 \mathrm{kN} / \mathrm{m}^{3}$ initial moisture volume percentage $\theta_{0}=0.11$; saturated moisture volume percentage $\theta_{s}=0.42$. we use EM4 3D geonet, and technical indicators are as (Table 1).

Table 1. 3D geonet parameters.

\begin{tabular}{|c|c|c|c|}
\hline Category & Mass Per Unit Area $\left(\mathbf{g} / \mathbf{m}^{2}\right)$ & Thickness $(\mathbf{m m})$ & Tensile Strength $\left(\mathbf{k N} / \mathbf{m}^{2}\right)$ \\
\hline EM4 & 350 & 14 & 2.0 \\
\hline
\end{tabular}

Based on the stability analysis model in this paper, the stability of $3 \mathrm{D}$ geonet slope protection system is calculated and evaluated under the condition of rainfall and non-rainfall respectively.

Under the condition of non-rainfall:

Actual thickness of mesh pads filling [11]: $\gamma_{s}=\gamma_{d}+\gamma_{w} \theta_{0}=17.6+10 \times 0.11=18.7 \mathrm{kN} / \mathrm{m}^{3}$

The formula (1-11) is derived according to formulae mentioned above:

$$
K=\frac{R}{S}=1.118
$$

The safety factor of 3D geonet slope can meet requirements, even if no anchoring under non-rainfall condition, and the result is as follows:

Under the condition of rainfall:

$$
K=\frac{R}{S}=1.014
$$

For the thickness of 3D geonet is small, it can be supposed that earth fill is saturated in a short time, so the unit weight of mesh pads filling under the condition of rainfall infiltration is:

$$
\gamma_{s}=\gamma_{d}+\gamma_{w} \theta_{\mathrm{s}}=17.6+10 \times 0.42=21.8 \mathrm{kN} / \mathrm{m}^{3}
$$

And

$$
K=\frac{R}{S}=0.8658
$$

The influence of rainfall on slope stability with 3D geonet is great, according to calculated safety factors in different conditions. Under the condition of non-rainfall, the stability can meet the safety requirements; while under the condition of rainfall, the stability can not meet the requirements, according to the existing construction specifications and technical requirements. Therefore, necessary measures should be taken in the early of 3D geonet slope protection 
system before lawn formation to ensure slope overall stability for avoiding unnecessary economic losses and casualties.

\section{FACTORS EFFECTING SAFETY COEFFICENT}

Slope stability is decided by rainfall intensity, slope angle, slope length, and rivet space and so on in the early of 3D geonet slope protection system before lawn formation. Based on the stability analysis model, the influence regularity of various factors on the $3 \mathrm{D}$ geonet slope stability can be studied.

3D geonet slope protection with greensward technology is often used on soil embankment slope with slope rate from $1: 1.5$ to $1: 2.0$, and when the rate goes over $1: 1.25$, other methods should be combined. Fig. (3) tells the slope safety factor change curve of different rivet space under the conditions that the slope angle is $40^{\circ}$ and the rainfall intensity is $30 \mathrm{~mm} / 12 \mathrm{~h}$. The figure shows that safety factor decreases rapidly with an increase of rivet space under the two boundary conditions, and the rivet space required by codes can not meet slope stability requirements.

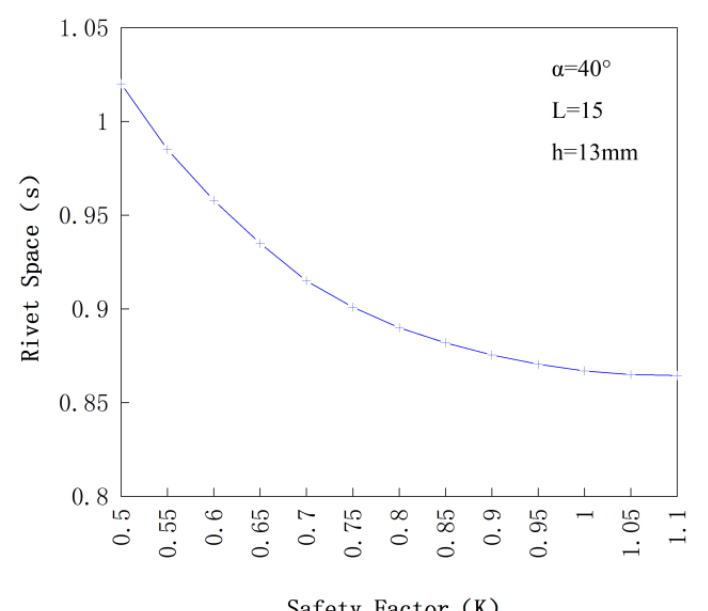

Fig. (3). The effect of rivet space on K under rainfall.

Fig. (4) is slope safety factor that changes curve of different slope angles and rivet space. The figure shows that the steeper the slope, the worse the protection system stability, the less the safety factors, and the degree of reduction goes down with increase of slope angle; at the same time, rivet space has little effect on safety factor K, when it goes over a certain value, no matter if the slope is steep or not. the property can be shown from the two K- $\alpha$ curves of $\mathrm{s}=1.2 \mathrm{~m}$ and $\mathrm{s}=1.5 \mathrm{~m}$ in (Fig. 4).

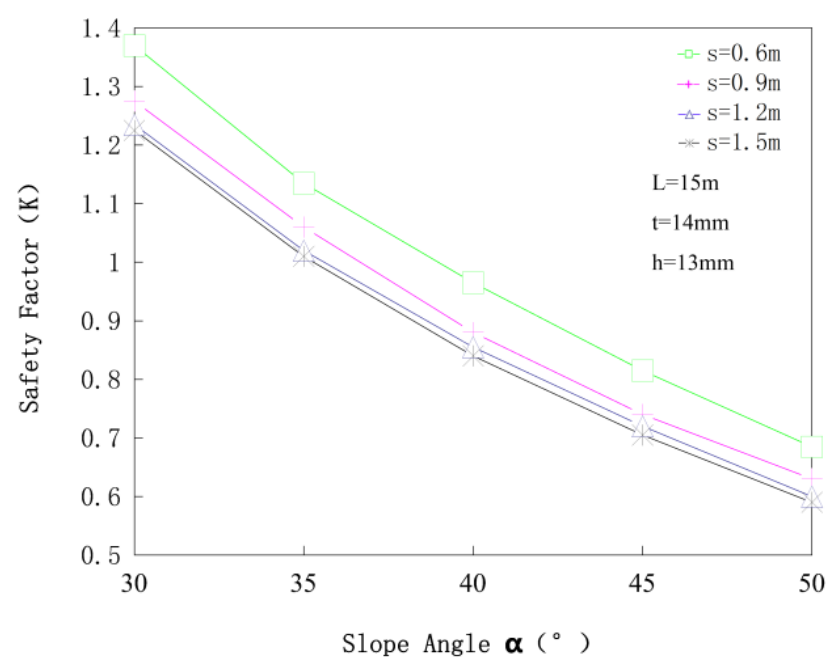

Fig. (4). The effect of rivet space and slope angle on $\mathrm{K}$ under rainfall.

With the increase of slope length L, anti-sliding force and sliding force of 3D geonet protection system increases. 
The calculated result shows that $\mathrm{K}$ increases with the increase of $\mathrm{L}$ in (Fig. 5). Therefore, the changing range of antisliding force is bigger than sliding force caused by L. Slope length can affect slope protection slightly and slope stability is good when the slope angle is less than $38^{\circ}$.

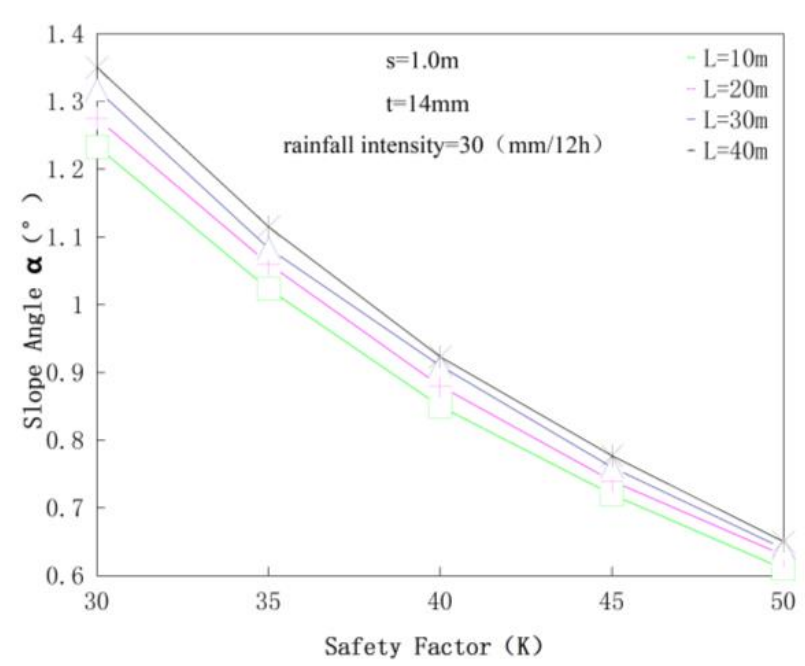

Fig. (5). The effect of slope angle and slope length on $\mathrm{K}$ under rainfall.

The changes of rainfall intensity have a prominent effect on 3D geonet protection system stability. Fig. (6) shows that rivet space has little influence on safety; and safety factor decreases rapidly with the increase of rainfall intensity. When the rainfall intensity goes over a certain value, it has little effect to reduce rivet space for the stability of $3 \mathrm{D}$ geonet protection system, and the two $K$-s curves whose $I=15 \mathrm{~mm}, I=30 \mathrm{~mm}$ shows the property.

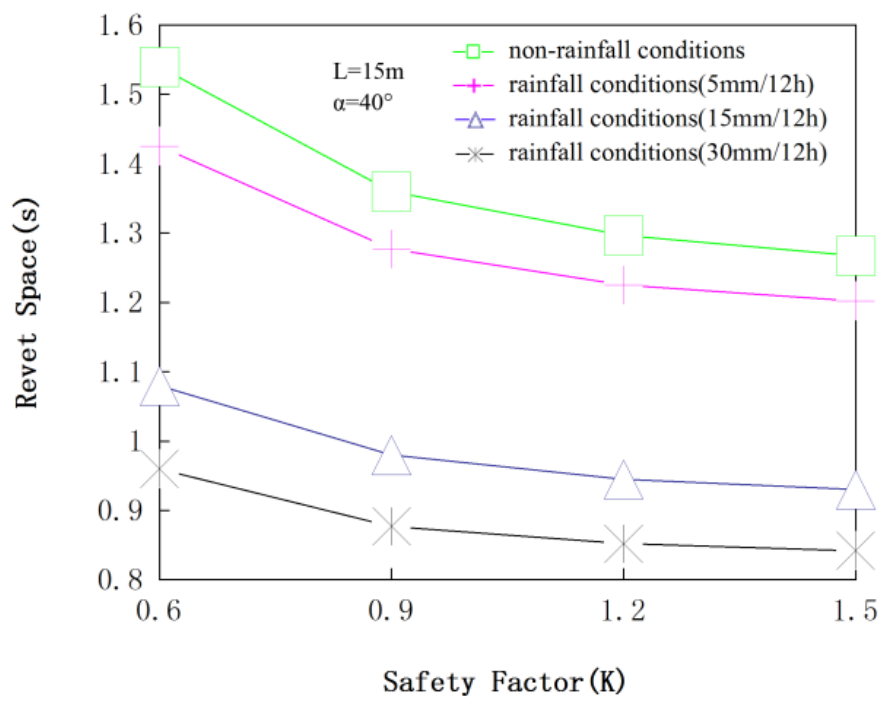

Fig. (6). The effect of rainfall intensity and rivet space on $\mathrm{K}$.

Under the condition of little rain or moderate rain, the rivet space required by codes can meet slope stability requirements, because there is small runoff or no runoff occurrence in short time under the condition of slight rainfall intensity, and the sliding force is small, as a result, the protection system can be stable by reducing rivet space to enhance anti-sliding force. However, the safety factor decreases rapidly, for the reason that mesh pads filling saturated rapidly, soil softening, large runoff shear force and seepage force under the condition of heavy rain. Therefore some certain protective measures should be taken to ensure slope safety stability under the condition of heavy rain. 


\section{OPTIMAZATION DESIGN OF RIVET SPACE}

$3 \mathrm{D}$ geonet slope protection is a shallow slope protection measure, and whether or not the vegetation net goes in effect is decided by the following two aspects: 1- status of vegetation in the early of building; 2- whether or not 3D geonet slope protection system can be effective in the early stage.

Rainfall, slope angle and rivet space is the three factors that play main role in the safety coefficient of 3D geonet slope protection system, according to the analysis of factors effecting safety coefficient mentioned above. Rainfall decided by climate mainly is harmful for protection system stability, and the slope angle decided by topographical factor is difficult to improve. Therefore, it is an effective measure to optimize rivet space design, according to unfavorable factors of slope protection system, which is of great significance to construct design of 3D geonet slope protection.

According to the formula (1) mentioned above:

$$
K=\frac{R}{S}=\frac{R_{j} / K_{j}+F}{Q+G \sin a+T+J_{D}}
$$

The minimum safety factor that can meet 3D geonet slope protection system is defined as $K_{\max }$, and the maximum rivet space $S_{\max }$ can be found out, by $K_{\min }$ :

$$
s_{\text {max }}=\sqrt{\frac{t f_{j} L}{k_{j} \times\left[K_{\min } \times\left(Q+G \sin \alpha+T+J_{D}\right)-F\right]}}
$$

According to the actual conditions of the project, for example the local average rainfall, project supposed slope angle, and slope types, the expression can be used to optimize rivet space design, which not only protects 3D geonet protection system from damage in the early of building, but also saves resources and avoids unnecessary wastes and property losses.

In the example mentioned above, the local rainfall intensity is supposed to $I_{12}=30 \mathrm{~mm}(\mathrm{~mm} / 12 \mathrm{~h})$, and other conditions are equal, then the following rivet space and slope angle project design parameters can be obtained by calculating the 3D geonet slope protection stability, as shown in (Table 2).

Form Table 2, it can be shown that 3D geonet slope protection works well when the slope angle is small, however, other effective measures should be taken to ensure slope protection system's stability when slope angle goes over $35^{\circ}$. The supposed slope angle is $40^{\circ}$ in the example, and the rivet space can not meet protection system stability requirements obviously when the protection system suffers heavy rain in the early of building.

Table 2. The relationship between safety factor and slope angle rivet space.

\begin{tabular}{|c|c|c|c|c|}
\hline \multirow{2}{*}{ Slope Angle } & \multirow{2}{*}{$\mathbf{3 0}^{\circ}$} & \multirow{2}{*}{$\mathbf{3 5}^{\circ}$} & \multirow{2}{*}{$\mathbf{4 0}^{\circ}$} & $\mathbf{4 5}^{\circ}$ \\
\cline { 1 - 5 } Rivet Space & 1.368 & 1.138 & 0.958 & 0.813 \\
\hline $0.6 \mathrm{~m}$ & 1.324 & 1.109 & 0.921 & 0.779 \\
\hline $0.7 \mathrm{~m}$ & 1.294 & 1.071 & 0.897 & 0.757 \\
\hline $0.8 \mathrm{~m}$ & 1.274 & 1.058 & 0.881 & 0.741 \\
\hline $0.9 \mathrm{~m}$ & 1.260 & 1.040 & 0.869 & 0.731 \\
\hline $1.0 \mathrm{~m}$ & 1.249 & 1.030 & 0.860 & 0.723 \\
\hline $1.1 \mathrm{~m}$ & 1.241 & 1.023 & 0.854 & 0.716 \\
\hline $1.2 \mathrm{~m}$ & 1.234 & 1.017 & 0.848 & 0.712 \\
\hline $1.4 \mathrm{~m}$ & 1.229 & 1.013 & 0.844 & 0.708 \\
\hline $1.5 \mathrm{~m}$ & 1.225 & 1.009 & 0.841 & 0.705 \\
\hline
\end{tabular}

\section{CONCLUSION}

(1) Based on rainfall infiltration, scouring and raindrop impact, we adapt the limit equilibrium method to analyse anti-sliding stability of 3D geonet protection system and builds a mechanic stability analysis model for 3D geonet slope protection of design and stability evaluation.

(2) Based on project example, influencing factors of 3D geonet protection system stability can be studied by 
value graphs method, and rule factors affecting stability are obtained. It shows that slope angle and rainfall intensity are the main unfavorable factors of 3D geonet slope protection system with safety stability.

(3) Under the condition of rainfall, especially heavy rain or strong rainfall, soil saturated and softening, shear strength decreasing, anti-sliding force decreasing, and large runoff flush and seepage force causes 3D geonet slope protection system of instability failure.

(4) The safety factor of 3D geonet slope protection system obviously decreases with the increase of rainfall intensity, rivet space, and slope angle. In this paper, the calculated slope angel of $3 \mathrm{D}$ geonet slope protection system should not go over $38^{\circ}$, which meets general rules of slope rate being no more than 1:1.25.

(5) Rivet space optimization design analysis of 3D geonet slope protection system is made, which provides theoretical support to generalize 3D geonet slope protection technique deeper.

\section{CONFLICT OF INTEREST}

The authors confirm that this article content has no conflict of interest.

\section{ACKNOWLEDGEMENTS}

This project was supported by the National Natural Science Foundation of China (Grant No. 11372165).

\section{REFERENCES}

[1] X. Xiao-hua, "Application of three-dimensional geonet sprig-grass for reinforcement of the side slope of bank", Port \& Waterway Engineering, vol. 30, no. 1, pp. 71-72, 2004.

[2] W. Zhi-qiang, "The application of three dimension geotechnical gauze pad combined with vegetative protection in slope", Shanxi Architecture, vol. 34, no. 8, pp. 279-280, 2008.

[3] Q. Tao, C. Guo-ping, and Z. Tuo, "Exploration of slope ecological protection of yushu airport in qinghai-tibet plateau area", Subgrade Engineering, vol. 27, no. 3, pp. 191-193, 2010.

[4] S. Yi-ming, Y. Liang, D. Guangsen, C. Yuqin, P. Jiang, Z. Qiong, and Z. Guike, "Experimental project of environmental protection vegetation on gangue dike slope of Huaihe River", Advances in Science and Technology of Water Resources, vol. 33, no. 4, pp. 22-25, 2004.

[5] X. Heng-lin, W. Zhao, and Z. Jin-feng, "Study on the design indexes of three dimensional geomat", Rock and Soil Mechanics, vol. 25, no. 11, pp. 1800-1804, 2004.

[6] X. Heng-lin, W. Zhao, and Z. Jin-feng, "Experimental study of properties of slope protection through grass jetting on 3D geomat", Journal of Chongqing University, vol. 33, no. 8, pp. 96-102, 2010.

[7] L. Xiao-lu, G. Qiang, and X. Heng-lin, "Slope protection technology of grass seeding based on 3D geomat", Journal of Yangtze River Scientific Research Institute, vol. 25, no. 3, pp. 58-61, 2008.

[8] X. Cheng-zhi, L. Xiao-peng, and S. Jian-cheng, "Research onmechanism of runoff- erosion prevention by 3- D mat planting grass for slope protection", Yangtze River, vol. 40, no. 19, pp. 93-97, 2009.

[9] Z. Zhi-Chang, Hydraulics. China Water \& Power Press: China, 2011.

[10] G. Li, "Erosion calculation of raindrops'kinetic energy of loess plateau's rainfall", Journal of Lanzhou Jiaotong University, vol. 24, no. 4, pp. 43-45, 2005.

[11] C. Shan-xiong, and C. Shou-yi, "Analysis of stability of unsaturated soil slope due to permeation of rainwater", Rock and Soil Mechanics, vol. 22, no. 4, pp. 447-450, 2001.

Received: January 26, 2015

Revised: July 24, 2015

Accepted: July 28, 2015

(C) Wang et al.; Licensee Bentham Open.

This is an open access article licensed under the terms of the Creative Commons Attribution-Non-Commercial 4.0 International Public License (CC BY-NC 4.0) (https://creativecommons.org/licenses/by-nc/4.0/legalcode), which permits unrestricted, non-commercial use, distribution and reproduction in any medium, provided the work is properly cited. 